\title{
Meat or wheat for the next millennium?
}

\author{
D. Joe Millward \\ Centre for Nutrition and Food Safety, School of Biological Sciences, University of Surrey, Guildford GU2 5XH, UK
}

This issue of the Proceedings of the Nutrition Society includes short papers from some of the principal speakers of a debate on the theme of the 1998 Summer Meeting of the Nutrition Society at the University of Surrey: meat or wheat for the next millennium? The theme has several important strands. For international food policy, the issue relates to provision of adequate and appropriate food for a global population estimated to rise to more than eight billion by 2025, with an increasing demand for meat in developing and especially transitional societies. In contrast, in affluent societies meat intakes are falling as part of the changing dietary patterns of animal and plant food associated with the healthy diet. The issues are particularly complex and range from the nutritional adequacy and bioavailability of various plant-animal food combinations in relation to human metabolic demand for nutrients to the chronic responses to varying patterns of food intake in terms of human health and well-being, and the complex psycho-social issues of why people eat what they do. The latter issue includes the is food bad for you?' question resulting from the headline issues of microbiological and toxicological hazards from meat and animal foods including salmonella, Escherichia coli, and bovine spongiform encephalopathy outbreaks, occurring with increasing frequency in the UK and seen by many to result from intensive animal food production. This situation provided the impetus for the proposal for a UK Food Standards Agency.

The debate was organized on the basis of what can loosely be described as two pro-meat (Hill and Golden) and two pro-veg presentations (Key and Sanders), followed by a general discussion, with summaries of the arguments of Hill, Key and Sanders published here (Hill, 1999; Key et al. 1999; Sanders, 1999). The formal presentations were of necessity limited to very specific themes, of which the potential adverse influence of meat on chronic disease was addressed by each side. Hill (1999) specifically defended meat from its purported role in the aetiology of colo-rectal (CR) cancer. This was a high profile issue in 1997-8 after the World Cancer Research Fund (1997) report on diet and cancer concluded that red meat probably increased risk of CR cancer and intake should be limited to $80 \mathrm{~g} / \mathrm{d}$. Department of Health (1998) also recently reported on diet and cancer with similar advice initially issued by the Government but subsequently revised to the suggestion that heavy meat-eaters (> $140 \mathrm{~g} / \mathrm{d})$ should cut back. Hill (1999) robustly challenged the strength of the epidemiological evidence for a meat-CR cancer risk relationship used as the basis for the World Cancer Research Fund (1997) recommendation, arguing it to be a serious error of judgement likely to lead to a confused subsequent public health message. He points to striking European population data on meat intake and CR cancer risk, with the UK now consuming relatively little red meat as a result of the marked fall over the last few decades, during which time CR cancer mortality has increased to levels near the top of the European average.

The surprising moment of the debate was the support for this view from the opposition. Key et al. (1999) presented findings of their own studies of the impact of meat-less diets on morbidity and mortality, including what are probably the most definitive data available on the issue. A collaborative analysis of 8300 deaths among 76000 men and women of quite similar lifestyles in five prospective studies showed that in comparison with non-vegetarians, vegetarians had a lower BMI and plasma cholesterol concentration and a reduced mortality from IHD, possibly associated with lower intakes of saturated fat. However, meat-eating had no effect on mortality from colon cancer or any other cause of death. Clearly, as Key et al. (1999) argue, the prevention of 40000 premature deaths from IHD by adopting a vegetarian diet is a compelling argument for this dietary change. If it proves to be a saturated-fat-mediated mechanism then that aspect of meat's influence in the diet needs to be the target of the public health message. However, an argument for an adverse influence of meat through a meat-CR cancer relationship increasingly appears unsustainable, at least on the basis of existing data.

Golden argued for the importance of meat in the provision of key bioavailable nutrients associated with child growth and development such as Fe, $\mathrm{Zn}$ and essential amino acids. Impaired height growth (stunting) is found in $>50 \%$ of young children in some parts of the developing world, with adverse influences on morbidity and mortality (Waterlow, 1997), along with retardation of mental development as shown very clearly in recent work in Jamaica (Grantham-McGregor, 1992). Furthermore, for those children eating the more extreme vegetarian diets consumed in developed countries, such as the macrobiotic diet which can be limited to little more than whole grains, and which seriously impair growth and development, Dutch studies 
have shown that modest interventions with animal products (either fish or dairy products) can alleviate such impairment (Dagnelie et al. 1994).

However, as pointed out by Sanders (1999) most vegetarian diets consumed in developed countries differ little in nutrient content from those containing meat, the issue being mainly limited to mineral bioavailability which may explain the poor Fe status of the UK Asian population whose diet is low in meat. Much of the debate in the West therefore focuses on the ethical and environmental issues relating to meat, which to many individuals means that reduced meat production and consumption are simple and obvious ethical and desirable acts. In fact an analysis of this issue proved to be a highlight of the meeting with most unexpected findings. Rosegrant et al. (1999), at the International Food Policy Research Institute (Washington, DC, USA), reported an analysis of the actual consequences for the extent of malnutrition in the developing world of consuming less meat. The case has been presented many times and is superficially simple. Feedlot beef production converts $7 \mathrm{~kg}$ grain into $1 \mathrm{~kg}$ meat. Thus, a reduction in beef production would be beneficial in increasing cereal availability for those in need in the developing world. Indeed, even higher costs for beef production have been presented. Rifkin (1992) calculated that beef production cost $90 \mathrm{~kg}$ feed $/ \mathrm{kg}$ together with 25000 litres water $/ \mathrm{kg}$, while adding approximately $60 \times 10^{6} \mathrm{t} \mathrm{CH}_{4}$ overall to the world's annual $500 \times 10^{6} \mathrm{t}$ atmospheric emissions. Rosegrant et al. (1999) report a detailed prediction of the consequences of a dramatic $(>50 \%)$ reduction in meat consumption in developed countries on food availability and the number of malnourished children under 5 years of age. Based on current trends of population growth, improved food supplies and food purchasing power, they calculate only a modest $21 \%$ fall in malnourished children by 2020. If meat consumption is halved, there will be a marginal improvement to a $23 \%$ fall, with an actual worsening for some countries (India). Through a complex number of interactions between prices of coarse grains used in cattle feed (which may fall) compared with those of rice and wheat (which will be less affected), and a shift in the demand for meat from the developed to the developing world (which would counteract any fall in actual meat production, and where any benefit of falling global meat prices will be offset by the inability of local meat production to compete with that available from the developed world, adversely influencing income and food purchase), a marked decline in livestock consumption in the West will have virtually no impact on food security in the developing countries. A sobering conclusion and demonstration of the dangers of oversimplification in the debate.

In fact, several delegates speaking from the floor raised the issue of implications of the debate for the developing world for whom increased meat consumption is a feature of development, and is seen as an entitlement by most populations. Meat consumption has always been a feature of celebration and ceremony, so increased consumption with increasing affluence is inevitable. It was stated that there is resentment of what is seen as a somewhat arrogant and proselytising attitude of developed world vegetarians, possessing purchasing power and food choice enabling the selection of varied and appealing meat-less diets (as served in my home for example), which are quite inconceivable to those in the developing world, and likely to stay that way on the basis of current projections. Clearly, whilst from a strictly nutritional perspective meat is an optional and non-essential component of the "Healthy diet', especially now some traditional attitudes to animal food sources are known to be clearly incorrect (such as the notion of first and second class protein; see Millward, 1999), nevertheless for a number of highly complex social, political and economic reasons meat occupies a pivotal position in the global food chain, which is unlikely to change much in the foreseeable future. The main conclusion from the debate was that public health messages about meat need to be formulated with more care than hitherto.

Philip James' usual energetic chairing of the debate unfortunately omitted to allow a vote on a suitable motion. However, this vote was taken at the conference banquet: beef Wellington or crown of lamb 100, warm parcels of roast vegetables 10 .

\section{References}

Dagnelie PC, van Dusseldorp M, van Staveren WA \& Hautvast JG (1994) Effects of macrobiotic diets on linear growth in infants and children until 10 years of age. European Journal of Clinical Nutrition 48, Suppl. 1, S103-S111.

Department of Health (1998) Nutritional Aspects of the Development of Cancer. Report on Health and Social Subjects no. 48. London: H.M. Stationery Office.

Grantham-McGregor SM (1992) The effect of malnutrition on mental development. In Protein-Energy Malnutrition, pp. 325-360 [JC Waterlow, editor]. London: Edward Arnold.

Hill MJ (1999) Meat and colorectal cancer. Proceedings of the Nutrition Society 58, 261-264.

Key TJ, Davey GK \& Appleby PN (1999) Health benefits of a vegetarian diet. Proceedings of the Nutrition Society $\mathbf{5 8}$, 271-275.

Millward DJ (1999) The nutritional value of plant-based diets in relation to human amino acid and protein requirements. Proceedings of the Nutrition Society 58, 249-260.

Rifkin J (1992) Beyond Beef: The Rise and Fall of the Cattle Culture. Washington, DC: EP Dutton.

Rosegrant MW, Leach N \& Gerpacio RV (1999) Alternative futures for world cereal and meat consumption. Proceedings of the Nutrition Society 58, 219-234.

Sanders TAB (1999) The nutritional adequacy of plant-based diets. Proceedings of the Nutrition Society 58, 265-269.

Waterlow JC (1997) Protein-energy malnutrition: the nature and extent of the problem. Clinical Nutrition 16, Suppl. 1, 3-9.

World Cancer Research Fund (1997) Food, Nutrition and the Prevention of Cancer: A Global Perspective. Washington, DC: American Institute for Cancer Research/World Cancer Research Fund. 